\title{
On the importance of social network sites in the transitions which characterize 'emerging adulthood'
}

\author{
Gianluca Frozzi*, Elvis Mazzoni \\ S.E.Fo.R.A. Lab, Faculty of Psychology, Alma Mater Studiorum-University of Bologna, Piazza A. Moro, 90, 47521 \\ Cesena (FC), Italy
}

\section{Abstract}

Modern-day economic and socio-cultural developments require people to be ever more specialized and mobile in their educational and professional choices. This is particularly relevant for 'emerging adults', that is to say, those who find themselves at that stage of life when their scholastic or university education ends, and they begin to make choices regarding their professional working life. Transitions between different activity systems, and changes of residence which they entail, make 'emerging adulthood' a particularly unstable period in which young people continually dissolve, create and recreate relationship networks of varying degrees of importance which are able to support them through these changes. Beginning with empirical evidence and theoretical starting points typical of the psychology of education and development, this contribution proposes a theoretical reflection which attempts to analyze the efficacy of Social Network Sites in facilitating and supporting emerging adults during their education and vocational training and the important transitions which they have to face as they develop.

Keywords: activity systems, emerging adulthood, social capital, social network sites, transitions

Received on 5 April 2011; accepted on 5 June 2011

Copyright (C) 2011 Frozzi and Mazzoni, licensed to ICST. This is an open access article distributed under the terms of the Creative Commons Attribution licence (http://creativecommons.org/licences/by/3.0/), which permits unlimited use, distribution and reproduction in any medium so long as the original work is properly cited.

doi: 10.4108/icst.trans.eeel.2011.e4

\section{Introduction: from external tools to functional organs}

People do not use Information and Communication Technologies (ICTs) solely for the joy of using them, or simply to interact with them; instead, they use them to create documents, communicate with others, to carry out certain projects and indeed for many other purposes; therefore, human-ICT interaction can be considered as a means of fulfilling a number of important goals [1]. In other words, considering the interaction between a man and a web tool, it is necessary that the human side of the system is able to easily comprehend and make use of the tool, rather than participating passively in the interaction. This possible passivity does not mean the control of man by the technological tool, but rather man's necessary adaptation to its characteristics. When the characteristics or modalities of the instrument's working do not meet

${ }^{*}$ Corresponding author. Email: gianluca.frozzi@gmail.com or do not support the idea that the user has of such technology, he is forced to 'bend' and 'adapt' his preconceptions to the physical and functional reality of the technological tool [2]. Two significant consequences may arise from this: firstly, a whole series of difficulties which characterize human-computer interaction (HCI), as clearly laid out by Norman [3] and secondly, the possibility of such tools being used in ways and for purposes other than those for which they were intended, as argued by Perriault [4].

Despite the widespread optimism about HCI for the successful analysis and study of human-ICT interaction, some authors [5-7] have for some time been highlighting certain important points; primarily the lack of an adequate consideration of the context, the purpose and the reasons for which human-ICT interaction takes place.

A contextual approach, which offers an answer to the considerations outlined above, is found in the Activity Theory (Engeström [8], Figure 1), a point of view which, despite being a relatively recent creation, has a theoretical 


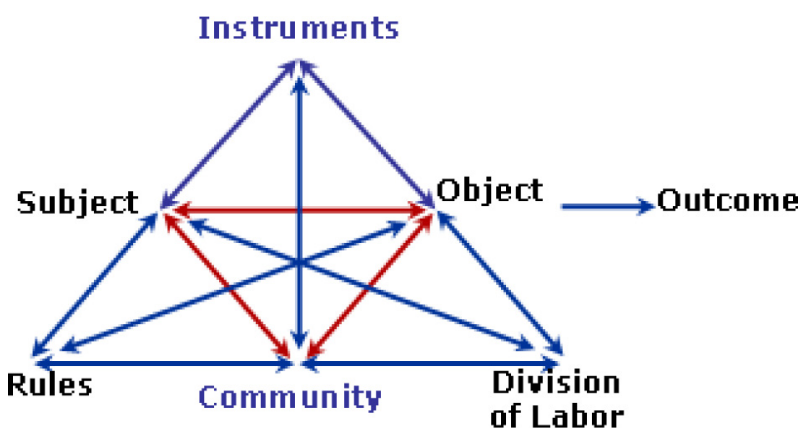

Figure 1. The human activity system representation in the Engeström's perspective (adapted from [23]).

basis which can be traced back to the first half of the last century, in the writings of authors such as Vygotsky [9] and Leont'ev [10].

Vygotsky's belief, with respect to the cognitive model outlined previously, is that man does not simply interact with a tool, nor does he respond instinctively to the pressures of his environment (as stated in the behaviorism theories which prevailed in the early 1900s); but instead the interaction between man and the socio-cultural environment which surrounds him is mediated by the cultural artifacts, or in fact, by any aspect of the material and symbolic world, constructed by human beings and modified by them in the course of their use, which regulate the interaction with the world and with others, in order to carry out an activity $[11,12]$. Beginning from the Vygotskian point of view, Engeström [8] has further widened the concept of mediation between man and his context, emphasizing the collective aspect, that is to say, the fact that mediation on the part of the technological artifacts occurs within an activity system constituted by a community of reference. Activity systems are found in complex and organized contexts. Examples can be drawn from schools, universities or companies characterized by their own rules (implicit or explicit), which mediate the relationship between the subject and the community itself, and by a division of responsibilities, of roles and of tasks of the people involved (Figure 1), which mediates the relationship between the community and the object of the activity.

To better understand an activity system, we here show the example of a virtual degree course (Figure 2), whose final goal is the degree and the object of the activity is the acquisition of knowledge.

Now, we must accept the opinion that mediation on the part of the web artifact no longer means considering just one, but two interfaces: one which mediates the interaction between the user and the artifact, and the other which mediates the interaction between the userartifact and their socio-cultural context. Such a duality poses an important question as regards the placing of the boundary which exists between the individual who

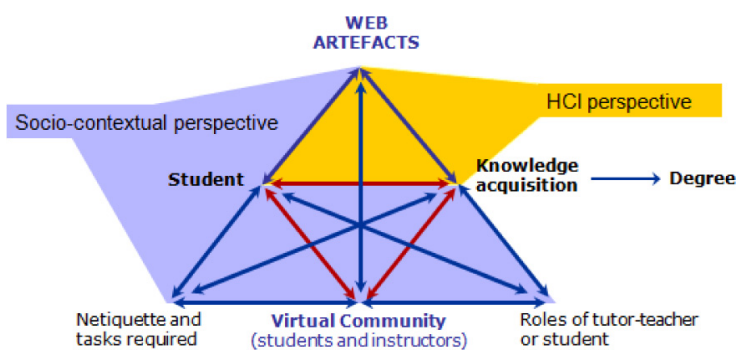

Figure 2. An example of an activity system of a virtual university course. Highlighted are the areas of investigation of $\mathrm{HCl}$ cognitive perspective and of the activity theory approach (adapted from [23]).

uses the tool, and his context: does this boundary coincide with that between the individual and the artifact, or with that between the artifact and the context?

An answer to this question can be traced back to the concept of functional organs [2, 10] i.e. functionally integrated 'tools' which represent internal and external resources aimed at achieving an objective. The external resources, for example, a pair of scissors, glasses or a diary, support and complement natural human abilities, enabling the construction of a more efficient system for obtaining a better result. Some examples can be made using the objects mentioned above: scissors allow us to cut something, 'transforming' the human hand into an efficient cutting organ; glasses improve man's sight; a diary supports a man's memory helping him to remember things more easily.

Obviously not all tools represent functional organs, in the sense that such a state comes about thanks to an evolutionary process directed toward the integration of an external instrument with one's personal abilities. The tools, which do not yet result as being functional organs (for example in the first phase of interaction with a tool when it is still necessary to learn how to use it), are conceived as belonging to the outside world; only when they have been integrated as a functional organ will they be considered as the individual's personal resources. A similar dynamic once again highlights personal expertise which, from this point of view, may indicate not only whether an individual knows how to do a particular thing, but also whether he has taken possession of a potentially useful instrument to do that particular thing, integrating it internally as a functional organ.

Beginning from the previous considerations and from Leont'ev's position, in this article we ask which characteristics of Social Network Sites (SNSs being one of the most representative web artifacts in the current ICT panorama) enable them to be considered as an extension of an individual's ability to create and maintain relationships, focusing in particular on individuals who find themselves having to face important transitions between different activity systems as they move from adolescence to adulthood. 


\section{Emerging adults and transitions}

Beginning with a review of existing psychological theories regarding the lifespan, Arnett in the USA proposes the concept of 'emerging adulthood' in order to identify the specific phase of development which takes place from, approximately, the end of high school until around the age of 30, with a focal point which, in industrialized Western countries, occurs more or less between the ages of 18 and $25[13,14]$. This period between adolescence and adulthood is particularly critical in the attainment of maturity as it is full of important transitions which lead to the structuring and refining of social skills in the long term, such as independence, professional orientation, and above all the construction and the upkeep of social relationships. It is a 'period of transition' in which one leaves behind the interdependence of the family, but at the same time has not yet entered into the permanent responsibilities of adulthood, the latter characterized by the acquisition of clearly defined roles including, for example, the creation of a nuclear family through marriage and parenthood or, in a professional context, having a fixed employment which enables one to provide for the family.

The salient characteristic of this phase appears to be instability, which is both historically and culturally rooted. In fact, from 1970 onwards industrialized Western countries have come up against significant and progressive demographic changes:

- First of all, due to the work-market's ever-increasing demand for specialized workers, there is a sort of democratization (someone speaks of 'massification') of higher education. In Countries of the Organization for Economic Co-operation and Development (OECD) the percentage of adults with degrees has nearly doubled in the period 1975-2000, from $22 \%$ to $41 \%$ (http://www.oecd.org). In Italy, during the last three years, the percentage of graduates in the general population has increased by $33 \%$, while remaining among the lowest in Europe. Also in countries characterized by an emerging and developing economies, like China or India, the student population has nearly doubled in the second half of the 1990s.

- Secondly, it is nowadays increasingly common for couples to postpone marriage until they have completed their university studies and found secure employment, causing the average age of marriage to rise staggeringly. Thus, in USA the mean age at first marriage for men has increased from 24.7 in the 1980 , to 26.8 in the 2000 until 27.6 of 2008 , while for women the mean age at first marriage has increased from 22 to 25.1, until 25.9 of 2008. In the same period, in Italy, the mean age at first marriage for man has increased from 27.2 in the 1980 , to 30.9 in the 2000 , until 32.8 of 2007 , while for women the mean age at first marriage has increased from 24.1 to 28.1 , until 29.7 of 2007 (http:// w3.unece.org-website of the UNECE, United Nations Economic Commission for Europe). Consequently the average age at which one has the first child has also increased.

These days, therefore, marriage and parenthood are events which, unlike in the past, take place at around, and perhaps even after 30 years of age. From data reported above it is clear that the same demographic dynamics reported above can be found throughout Europe as a whole, as noted by Arnett [15, 16], and also by Bynner [17] and Douglass [18] in the documentation of the historical decline in the birth rate throughout Europe. Thus, today's industrial society, at a global level, is characterized by a culture in which young people, during their time at university, are increasingly free from roles and social expectations which are typical of adulthood. Thus, unlike in the past, the industrialized societies of today permit emerging adults a greater amount of time to learn, to develop and to train and, consequently, to prepare themselves to face a global economic climate increasingly based on information, knowledge and on the extensive use of ICT.

In brief, Arnett depicts many trends of young people between 18 and 30 in occidental society, different from those characterizing their contemporaries in the past, that from his point of view justify the definition of a specific period in human development, that of emerging adulthood, separated from adolescence and adulthood $[13,15,18]$. Other authors [17, 19] are not so persuaded about the concept of emerging adults and they highlight two important aspects:

- First, not all the areas of development evolve at the same time and with the same speed; e.g. Baltes $[20,21]$ shows that human development is domain-specific and not something linear.

- The socio-economic and institutional conditions of countries influence the lifestyle of young people much more than Arnett considers. In fact, he gives lot of importance to individual factors and to opportunities, disregarding structural factors and limits defined by the life contexts but 'modern developmentalists have claimed that emerging adulthood is not a universal stage but depends on the cultural context in which young people develop and the social institutions they encounter' [19, p. 75].

These different points of view have aroused a very interesting debate between these authors and the result is a book in which all their positions are argumented [22].

A critical element, however, which is implicit in what has been described thus far, is instability, typical of this period and principally due to multiple transitions which 
emerging adults find themselves having to confront, among which we must note:

- The transition between various activity systems [8], such as college, university and the world of work. With 'activity system', we make an explicit reference to the 'activity theory approach' which views human activities as being finalized by an outcome and characterized by three main elements (subject, object and community), the relationships between which are mediated by three further entities, (rules, division of labor and instruments), as previously described. Among the mediating elements, in accordance with the Vygotskian view, an essential role in the relationship between subject and object is played by cultural artifacts $[23,24]$. The challenge inherent in such transitions is to acquire suitable and sufficient knowledge and skills to fulfill the expectations linked to the new social-cultural environments which emerging adults must deal with.

- The changes of residence necessitated by the transition between the different activity systems previously mentioned (going to college, moving from college to university or beginning to work after college or university) or simply by the choice to live alone. Studies conducted by Rindfuss [25] and Goldscheider [26, 27] show that, with respect to people of other age groups, emerging adults face the greatest number of changes of residence which begin at the age of 18 or 19 , when many young Americans leave home [28].

In addition to the aspects previously mentioned, Goldscheider's studies $[26,27]$ have also outlined the trend in changes of residence throughout the 20th century, highlighting in particular how, since the 1990s, the percentage of young people in the phase of emerging adulthood who leave home to live alone has progressively increased, to the detriment of the percentage of those who instead leave home in order to get married. Emerging adults rarely have a clear idea of where they will go to live from one year to the next: in the USA the first move is usually connected to leaving home in order to go to college, to work or simply to live alone in attempt to gain more independence from the parents; successive moves, however, are often due to unforeseen events such as the temporary or definitive suspension of studies, or a change of job. Therefore, leaving home is only the first important change of residence, which is later followed by many others which may, sometimes, involve returning to live with the parents.

\section{Risks linked to transitions and changes of residence}

As previously described, the emerging adulthood is a life period characterized by strong instability that takes also the form of transitions and residential changes that can cause difficulties in adaptation to new life contexts.
The transition between various activity systems and the consequent changes of residence involves risks and places demands on the social capital of an individual, which he or she has to cope with. By 'social capital' we generally refer to those resources which are created and accumulated through the relationships between individuals [29] or, to be more specific, 'the sum of the resources, actual or virtual, that accrue to an individual or a group by virtue of possessing a durable network of more or less institutionalized relationships of mutual acquaintance and recognition' [30, p. 14]. At the level of the individual there is evidence of the fact that social capital may correlate to some aspects of psychological well-being, such as self-esteem and satisfaction with life [31, 32]. At the level of the individual social capital allows each person to capitalize on their relationships with others and draw benefits from them, such as support or information. First among the main risks to the development and maintenance of social capital is that of losing contact with people met previously, who were part of a social network constructed before the transition to the new activity system. Previous ties can of course be characterized by the fact that they are stronger, such as with family and close friends, who typically offer emotional and motivational support, as well as affection; but may be also less intense, such as casual acquaintances or people known only by sight, who typically supply practical support, information, contact and alternative points of view.

Langston and Cantor [33] noted that many students who have a negative experience of the transition from one place to another experience disappointment particularly in the part of their lives concerning friendship and social relationships. Paul and Brier [34] define 'friendsickness' as the fear of losing contact with one's own friendship group (above all high-school friends, with whom, in the USA, a strong sense of belonging is often formed). They have also examined the number of friendships present in the social networks which they surveyed, noting that the students who showed signs of friendsickness had a greater number of friends from before college compared to the number of new friends made during their time at college and, as further confirmation of this 'backward investment' concerning the sense of loss, many of these students only thought about their pre-college friends.

Contemporaneous to the risk of losing a network of friends constructed before the transition (and to the necessity to confront this) is also the need to establish new social relationships in order to adapt well to one's new place of residence, of which one may have very little knowledge.

Further, the transitions from secondary school or college to more complex activity systems represent a significant challenge for emerging adults since the knowledge and competences with which they begin may not match those now necessary, and they are thus called upon to 
acquire new or update existing knowledge and competences on the basis of the requirements of the new activity systems.

From what has thus far been described, it is somewhat evident that during the important transitions which characterize emerging adulthood, individuals need tools which allow them not only to maintain social contacts, but also to reduce the gap between the knowledge and skills which they already possess, and those which are required by the new activity system [35]. Wenger [36] affirms that the frontiers between the knowledge and competences required by different activity systems can be overcome by three types of 'bridge': people, tools (artifacts) and relationships. But which people and which relationships would appear to be the most effective in the role of 'bridges'? Regarding this point we may take into consideration the contribution of Granovetter $[37,38]$ who demonstrates the importance of weak ties with respect to strong ties during critical situations which cannot be solved by the information and knowledge already possessed by the individual. People who are outside the individual's close circle of friends could be more likely provide useful information and/or new and valuable possibilities for action, whereas strong ties are characterized by supplying redundant information as the individual already shares their knowledge and often comes from the same social background [23]. The sum of the weak ties possessed by a person forms the foundation of the so-called 'bridging social capital', defined by Putnam [39] as that type of social capital deriving from the relationships with people to whom one is not close, such as acquaintances and friends of friends. These relationships typically provide practical support, information, contact and new points of view, as opposed to the emotional support, motivational support and affection which is instead supplied by the sum of an individual's strong ties, for example between family members and close friends, or rather the 'bonding social capital' [39].

\section{SNSs as 'bridges' to cross the boundaries of knowledge between different activity systems}

Some recent research and theoretical contributions have analyzed the importance of the online connections in the formation of weak ties, the core concept of bridging social capital [40], and have highlighted the important role played by web artifact 2.0 (especially SNSs such as Facebook, LinkedIn, Myspace, etc.) in permitting emerging adults to $\log$ on and keep in touch with their friendship group [23]. Other academics suggest that emerging adults use the web and particularly SNSs for 'bringing people and issues from their offline worlds into their online ones' [41, p. 421]. Even though some study has been devoted to the description of SNSs users and their use of these tools [41, 42], nowadays it is difficult to say whether online users have more benefit than offline users in terms of social capital derived from web utilization.

However, a fundamental concept, which allows us to better understand the integration between the real world and the virtual one, is that of 'latent ties', or rather, the type of tie which is specific to virtual connections, as it is 'technologically possible but not activated socially' [43, p. 137]. In Haythornthwaite's view [43], the introduction of a new medium into a group of people provides a means of including in their group people who would otherwise remain strangers, insofar as it puts at the disposition of the subjects a network of connections which is immediately useable at a technical level, leaving it up to them to decide the most opportune moment for actual activation at a social level, depending on the circumstances and the constraints which they have to meet. Such virtual infrastructures therefore support social ties which can be defined as latent because they are made possible by technology, but are, as yet, neither socially activated nor, necessarily, activateable. From initial knowledge based solely on the information available, for example, from a certain person's profile on an SNS or from mutual 'friends', the actual activation of social interaction (brought about by the necessity to ask for information or knowledge which the individual believes this person may have) transforms latent social ties into weak ties which, at this point, represent an effective resource for the individual's social capital. Social Network Sites allow people to interact and to create links with strangers, which would probably never come about in another way. These technological infrastructures may therefore act as 'bridges' which link people socially. Subrahmanyam et al. [41] propose a view in which web tools are thought of as interaction spaces in which emerging adults $\mathrm{cO}^{-}$ construct their online environment, psychologically connected to the offline one.

Despite the positive aspects outlined above, SNSs have also negative effects on their users, in particular as regards a sort of social network addiction which is strictly connected to a low self-esteem, depression and, first of all, a lack of social skills [44, 45]. In public opinion and in newspaper articles there is also the idea that this lack of social skills could derive from the types of ties which characterize SNSs. Indeed, many relations in SNSs are weak ties, characterized by simple contacts for delivering information, while the offline life is principally characterized by strong ties principally based on discussions. However, as shown by authors like Granovetter [37, 38] and Putnam [39], in some critical periods the weak ties play a fundamental role for solving the situation, allowing to access a set of information that strong ties could not guarantee.

On the basis of the theoretical discussion outlined above, the question, which we pose and which we hope to answer within this article, concerns the usefulness of SNSs in the transitions which take place during the stage 
of life which we have defined as 'emerging adulthood'. In particular, we ask whether SNSs may represent an effective cultural and mediating tool for emerging adults during these transitions, with the dual function of both maintaining and increasing their social capital, and of supporting them in their moves from one activity system to another.

\section{SNSs: maintaining contacts, developing social network, sharing information and constructing knowledge}

According to Haythornthwaite [43], web artifacts such as SNSs provide, both at a technical and social level, the tools for initiating interaction. Today, SNSs represent one of the most important Internet phenomena, and perhaps the most important online tool for allowing people to connect with each other, not to mention for giving people quick access to information about acquaintances and strangers with whom they may need to get in contact. For these reasons they also represent one of the most innovative recent tools of online communication, so much so that it is in fact possible to list at least one SNS linked to the majority of web activity (for example LinkedIn for professionals from various working sectors, ResearcGate for scientific research, Facebook for students, though not exclusively, and for free time, MySpace mainly for music, and so on).

The most distinctive characteristics shared by websites of this type concern the fact that SNSs permit the users [46]:

- to create a personal profile (Figure 3) and to decide whether to make it public, semi-public or more private;

- to select their own personal friendship network with whom they can share different types of information;

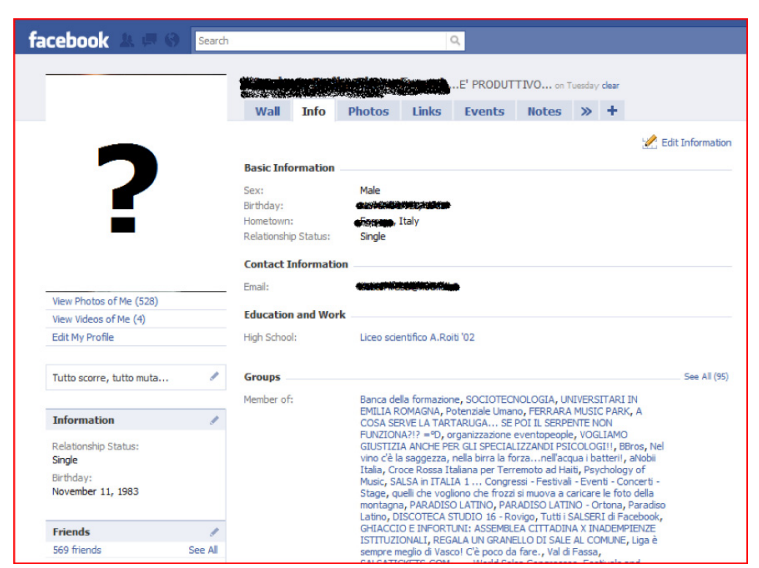

Figure 3. Profile of a hypothetical student on Facebook (image taken from the original on www.facebook.com).
- to have access to, or to simply be able view an entire range of information and data about other users, such as their friends, their photographs and videos, their interests, but also information of a much more personal nature like gender, occupation, hobbies, etc. (Figure 3).

By looking at the profiles of other users who may be known only by sight, or who one may not know at all but who one has heard of (latent ties), one is given access to information about their identity, their interests, hobbies, knowledge, skills, and so on, thus giving the individual the possibility to discover things they may have in common which could facilitate contact and provide an incentive for new social interaction. For example, Before I Graduate College (http://www.beforeigraduatecollege.com/) is an SNS dedicated to high schools and college students in which they can share objectives (goals) that they want achieve before their degree. By constructing networks of relations and by sharing their aspirations, students can compare each other about their ideas and experiences they would like to try, and maybe they can find other people that are willing to share and realize these experiences in real life (e.g. going away for an internship or a stage abroad). Further, by visiting the Facebook profiles of students at the universities where one intends to apply, a student can get in contact with them in order to obtain information about applications, the possibility of finding accommodation in the area, or the difficulties that other students may have encountered when they began university, etc., thus beginning a sort of pre-socialization with the new activity system which they are about to enter. The same goes for the world of work. These simple and brief examples show how SNSs may represent a cultural tool capable of stimulating contact with new acquaintances and interaction between people, signifying for the participants an important 'bridge' which they can use to integrate themselves and to share and have access to information and knowledge which may be of varying degrees of usefulness. Of course, all of this is with a view to an easier and more rapid socialization within the new activity system in which the individuals are moving. As Mazzoni and Gaffuri [23] argue, SNSs facilitate the conversion from latent ties into weak ties since:

- these web artifacts allow students to access a wide variety of personal information about their contacts (and potential contacts);

- they make explicit the personal network of acquaintances;

- and finally they represent an important support system for emerging adults who need to identify people that could be helpful in specific situations.

But these SNSs are not used simply for creating and maintaining contacts. Some scholars [47-49] have already 
analyzed and stressed the importance of these web artifacts for education and vocational training. Based on the argument made previously about transitions, faced with the difficulties and needs of creating new relations in a new activity system, an SNS allows a student to have a wide set of contacts technologically always at disposal [43], that could become socially activated when the student needs an help as regards the study courses and the requested knowledge construction. For example, Santos et al. [50] have found that a sample of Brazilian students, enrolled in a Master of Education at a Brazilian University, used SNSs not only for keeping in touch with their social network, but also for discussing about the activities related to their study courses and in some cases also for maintaining professional contacts. In particular, the students answered to use SNSs for sharing information and discussing with each other about activities, ideas and resources connected to their studies, by stressing the importance of discussion groups with other members of the SNSs enrolled in the same Master. As regards this last point, students affirm that SNSs discussions allowed them to better understand the course's contents and to share knowledge for having further ideas about the activities to accomplish. In general, all students agreed that SNSs were important not only for constructing and maintaining contacts, but also for constructing knowledge related to their studies [50].

Also for teachers, SNSs could represent creative tools for maintaining a more informal contact with students [51] and, also, for allowing students with a quick and easy contact for solving problems or doubts during their homework. By means of specific SNSs having educational and vocational objectives (like http://www.ning.com/ or http://www.elgg.org/), teachers could create network spaces dedicated to specific group discussions with their students on course's subjects, allowing students to collaborate and discuss with invited experts in the field.

From what has so far been outlined about SNSs, we can certainly affirm that, today, these cultural tools represent the easiest way for emerging adults to keep in contact with an already-established friendship group during a period in their lives which is characterized by certain important transitions. By providing them with the means to do this, as Ellison et al. [40, 52] have emphasized, SNSs allow them to maintain their bonding social capital and, at the same time, facilitate and support them in beginning new social interaction, thus also, and above all, increasing their bridging social capital. A further aspect which is particularly significant regarding SNSs, and as a consequence of what has been highlighted above, is the important support which they offer in the finding and exchange of information, not to mention in the co-construction of informal acquaintances [23]. From this point of view, SNSs can be seen as an important online social 'environment' for the construction and sharing of 'boundary objects' [53] capable of helping emerging adults deal with possible gaps in knowledge and skills, due to the 'frontiers' which define one activity system from another. An explication of the potentiality of SNSs in mediating the transition between two activity systems derives from the concept of functional organ previously introduced $[2,10]$. Thus, an SNS can be seen as the 'technical' side of a functional organ that integrates the web artifact and the human ability to construct and maintain social relations.

Integrating and matching knowledge and skills acquired and used within a certain activity system with those required by the new activity system can be an arduous and difficult undertaking, clearly made smoother by the possibility of contacting and interacting with people who are already settled in the new reality which one is about to enter. As noted by Star [54], 'boundary objects' play an important role in coordinating different points of view of the 'actors' who are aiming to reach a common goal. In other words, 'boundary objects' can be seen as something (an idea, a common point of view or, in this case, a virtual cultural tool like an SNS) which permits the crossing of the 'frontiers' between two different activity systems.

One can also think of 'boundary objects' as a sort of scaffolding which may be used in order to extend one's personal knowledge and skills both inside and outside the zone of proximal development. This last concept refers to the difference between the result that a subject is able to obtain when working alone, and that which he or she would be able to obtain if, rather than operating alone, they were supported by other individuals of equal or greater expertise $[55,56]$. The construction of a common area of interest, in which individuals are able to share knowledge, information, messages, skills and points of view, allows the different 'actors' who are acting in favor of a common goal, to create a 'bridge' by which they can integrate information and knowledge which distinguish one activity system from another. For example, the possibility of contacting students at the university where an individual wants to enroll, before going there in person, can be a genuinely important chance to exchange useful information (about the matriculation, for finding an accommodation, for some difficulties encountered at the beginning, etc.) and to begin a sort of pre-socialization with the new activity system in which he/she is entering. Let us imagine, for example, that at the end of high school a student (in Figure 3 we see the profile of this student, with the relevant information) chooses to continue his studies at the Psychology Faculty at the University of Bologna, which is at a considerable distance from his current hometown.

$\mathrm{He}$ decides to make use of the possibilities offered by Facebook, on which he is a registered user, in order to find useful information regarding his new faculty, so as to have some initial contact with the institution in which he intends to enroll and with people (students in particular) who are already a part of it. Using the SNS's search engine (Figure 4, left), the student is able to find various 


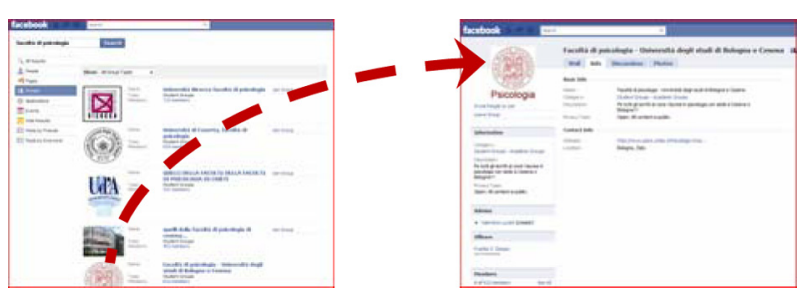

Figure 4. Student's search (left) and enrollment (right) in the Facebook group dedicated to the students at the Psychology Faculty in Bologna (image taken from the original on www.facebook.com $)$.

groups relating to the faculty of psychology in various Italian universities, among which there is also a group dedicated to the faculty of psychology at the University of Bologna, managed by students who already attend this faculty, and so he signs up.

Exploring the page dedicated to the faculty, he finds links to the profiles of all the members of the group (Figure 4, right), including its administrators and those responsible for the page. The student can now exploit the multiple tools at his disposal on the site in order to get in contact with these people, many of whom, already being a part of the activity system 'University of Bologna, Psychology Faculty', already possess the information which the student is looking for (for example, information about accommodation, course content, the difficulty of the work) or they may be able to tell him about other people who may be able to supply him with the information he needs. This example clearly shows how SNSs might allow people to keep in touch with other people more effectively, since by surfing within the users' social networks they can reach the appropriate person to ask for information or to receive an answer. The student can, for example, leave a message on the group's public notice-board and wait for other members to answer his 'call', or he could use the chat or email services, or even ask to become friends on the site with the group administrator in order to explain to him/her what he requires or even click on the link directed to a site of interest often visible on the groups page of an SNS. By doing so, the student has the possibility to contact quickly and efficiently, without needing to go anywhere or spend anything, people with whom he would never otherwise have the chance to interact. Therefore, the latent technological ties available on Facebook, according to frequency of interaction, can be transformed into weak ties and thus increase the social capital of the student and further expand his potential methods for finding information and exchanging knowledge. Thus, there may be a reduction in the gap in knowledge and competences between the different activity systems.

Social Network Sites can be visualized as social environments, activated by individuals, for the reciprocal construction of relationships. From our point of view, these web artifacts are therefore not intended to be tools which merely define spaces of virtual socialization in which conversations, discussions or the exchange of information take place passively, such as what happens with web artifact 1.0; but they can primarily be viewed as virtual social spaces which allow individuals to cross the thresholds between old and new activity systems, and to extend their knowledge toward what is required by different activity systems [23].

The Social Network site, LinkedIn, for example, like other SNSs in the professional domain (such as https:// www.researchgate.net/ or http://www.academia.edu/) proposes two specific ways of tracing latent ties and of activating social contact. Firstly, the internal search engine, which allows one to research professions similar to one's own on the basis of the key words inserted (Figure 5).

Furthermore, on one's personal homepage, LinkedIn suggests a list of people who the user may know directly or indirectly as they are part of the network with which he has already activated a connection (Figure 6).

In such a way, LinkedIn allows users to quickly trace people in their own professional sphere, who they may ask for information or with whom they can share knowledge.

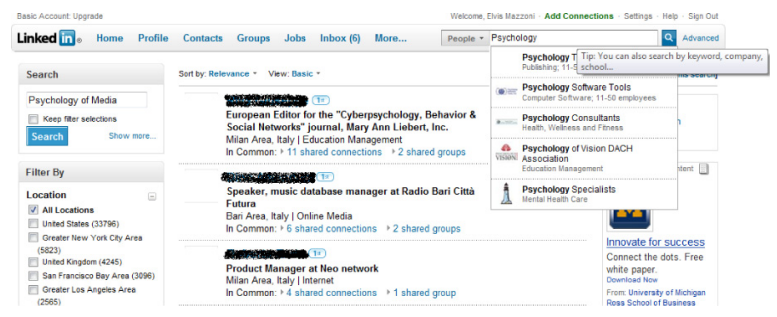

Figure 5. The search engine of the SNS LinkedIn and the results of a search (image taken from the original www.linkedin.com).

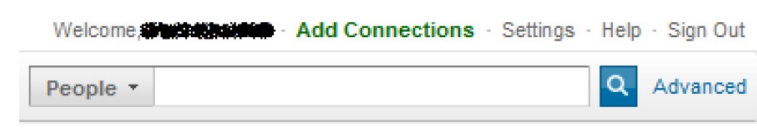

\section{Iscriviti gratis su Experteer.it!}

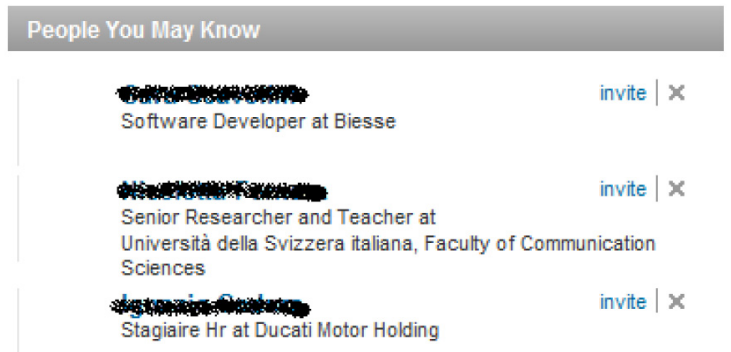

See more people you may know

Figure 6. An example of latent ties suggested in People You May Know on LinkedIn (image taken from the original on www.linkedin.com). 
The shift from latent ties to weak ties, facilitated by the infrastructure offered by web artifacts, thus permits emerging adults to increase their bridging social capital and to draw from it the benefits previously outlined. The social networks visualized in SNSs appear to be structurally broad and heterogeneous, as a collection of weak ties similar to those defined by Granovetter [37], and this assumption is particularly clear in the results obtained by the studies conducted by Ellison et al. [40, 52]. The results of their research on the use of Facebook by college students illustrate the importance of this SNS for developing and maintaining relationships during changes of residence, thanks to the fact that this web artifact represents an effective way, both technically and socially speaking, of keeping in contact with friends and acquaintances made prior to the move, without excluding the possibility of forging new friendships, beginning with latent ties [52]. In the view of the authors, the capacity of Facebook to facilitate the activation of contacts and communication (typical of all SNSs) could be of particular support to students with low self-esteem, inasmuch as it may reduce their fears of rejection, thus explaining why such students seem to obtain greater benefit from the use of Facebook with respect to those students with higher levels of selfesteem (who nonetheless benefit from the site as they are able to use it in order to expand their friendship network). Furthermore, Mazzoni and Gaffuri [23, 24] suggest that the so-called 2.0 web artifacts, the 'new generation' of web tools (blogs, wikis and above all SNSs), may be more effective than the previous 1.0 artifacts, that is to say, the classic message boards and web forums, for crossing the frontiers of knowledge which characterize different activity systems during the transitional phase of emerging adulthood. As we have outlined above, during this period emerging adults face many changes, moving through various activity systems.

While 1.0 web artifacts are largely characterized by a formal participation in which students often play a passive role, 2.0 web artifacts are much more likely to be characterized by informal participation [57] and by greater flexibility, which allows the students to manipulate their own personal space and to build their own relationship network. In this space they can interact privately with another individual and they can also choose the level of interaction to adopt with their social network: they may have personal interactions (such as messages which appear in the user's personal space, accessible to all their friends), they can interact with their personal network of contacts (by creating specific groups for example), or they may interact with the entire network, as would normally happen in the case of a web forum. The possibility to see information about one's friends, about their activities, events and friendships, simply by connecting to the internet, allows emerging adults to have a permanent means of keeping in contact with them, of keeping up to date with new opportunities and events and of being involved in the co-construction of informal acquaintances, without necessarily having to contact them directly or to meet them in person. Nowadays, SNSs represent the easiest and most effective way for emerging adults to keep in contact with their social network and to reinforce their bridging social capital, with just the click of a mouse. In our opinion, such a success is due to the very intrinsic characteristics of these systems which integrate perfectly with the human necessity to maintain social relationships in certain critical circumstances. Social Network Sites can in fact be seen as an extension of an individual's ability and capacity to create (as in the case of latent ties) and maintain relationships (such as in different levels of interaction which are made possible by these web tools), supporting the individual virtually, when physical distances create an insurmountable barrier for the development of human social capital.

\section{Conclusions}

This contribution is a theoretical reflection which, beginning from empirical evidence and other literary contributions, attempts to analyze the efficacy of SNSs in facilitating and supporting young people in the period of life defined as 'emerging adulthood', and during the important transitions which they find themselves having to face. On the basis of the theoretical views outlined at the beginning of this article, and of the data emerging from other research which has been conducted in this field, the conclusion that we are able to draw is that SNSs represent important web artifacts at the disposition of emerging adults, capable of supporting them both in the maintaining and developing of their social capital (and in combating the feeling of friendsickness), and in the construction of a background of necessary knowledge during the transitions between different activity systems [23].

As SNSs are typically characterized by relationships, these tools appear to offer a dynamic and adaptable social space in which weak ties can be developed and maintained with a degree of involvement which is not as high as that required in face-to-face relationships.

\section{References}

[1] Kaptelinin, V. (1996) Activity theory: implications for human-computer interaction. In NARDI, B. [ed.] Context and Consciousness-Activity Theory and HumanComputer Interaction (Cambridge, MA: The MIT Press), chap. 5.

[2] Mazzoni, E. (2006) Websites usability: cognitive versus activity theory approaches. In ZAPPALA, S. and GrAY, C. [eds.] Impact of e-Commerce on Consumers and Small Firms (Aldershot, Hampshire, UK: Ashgate), chap. 11.

[3] Norman, D.A. (1988) The Psychology of Everyday Things (New York: Basic Books).

[4] Perriault, J. (1989) La logique de l'usage (France: Flammarion). 
[5] Bannon, L.J. (1990) A pilgrim's progress: from cognitive science to cooperative design. AI Soc. 4(4): 259-275.

[6] Kuutti, K. (1996) Activity theory as a potential framework for human-computer interaction research. In NARDI, B. [ed.] Context and Consciousness-Activity Theory and Human-Computer Interaction (Cambridge, MA: The MIT Press), chap. 2

[7] Norman, D.A. (1980) Twelve issues for cognitive science. Cogn. Sci. 4: 1-32.

[8] Engeström, Y. (1987) Learning by Expanding: An Activity-Theoretical Approach to Developmental Research (Helsinki: Orienta-Konsultit).

[9] Vygotsky, L.S. (1981) The genesis of higher mental function. In Wertsch, J.V. [ed.] The Concept of Activity in Soviet Psychology (Armonk, HY: Sharpe).

[10] Leont'Ev, A.N. (1974) The problem of activity in psychology. Sov. Psychol. 13(2): 4-33.

[11] Cole, M. (1996) Cultural Psychology: A Once and Future Discipline (Cambridge, MA: Harvard University Press).

[12] Cole, M. (1999) Cultural psychology: some general principles and a concrete example. In Engeström, Y., Miettinen, R. and Punamäki, R.L. [eds.] Perspectives on Activity Theory (Cambridge, MA: Cambridge University Press), chap. 6.

[13] ArnetT, J.J. (2000) Emerging adulthood: a theory of development from the late teens through the twenties. Am. Psychol. 55: 469-480.

[14] Arnett, J.J. and Tanner, J.L. (2006) Emerging Adults in America: Coming of Age in the 21st Century (Washington, DC: APA Books).

[15] ARnett, J.J. (2006) Emerging adulthood in Europe: a response to Bynner. J. Youth Stud. 9(1): 111-123.

[16] ArnetT, J.J. (2007) Emerging adulthood: what is it, and what is it good for? Child Dev. Perspect. 1: 68-73.

[17] Bynner, J. (2005) Rethinking the youth phase of the life course: the case for emerging adulthood? J. Youth Stud. 8: 367-384.

[18] Douglass, C.B. (2007) From duty to desire: emerging adulthood in Europe and its consequences. Child Dev. Perspect. 1: 101-108.

[19] Hendry, L.B. and Kloep, M. (2007) Conceptualizing emerging adulthood: inspecting the emperor's new clothes? Child Dev. Perspect. 1: 74-79.

[20] Baltes, P.B. (1987) Theoretical propositions of life-span developmental psychology: on the dynamics between growth and decline. Dev. Psychol. 23: 611-626.

[21] Baltes, P.B. (1997) On the incomplete architecture of human ontogenesis: selection, optimisation, and compensation as foundations of developmental theory. Am. Psychol. 52: 366-381.

[22] Arnett, J.J., Kloep, M., Hendry, L.B. and Tanner, J.L. (2010) Debating Emerging Adulthood: Stage or Process? (Oxford University Press).

[23] Mazzoni, E. and Gaffuri, P. (2009a) Personal learning environments for overcoming knowledge boundaries between activity systems in emerging adulthood. eLearning Pap. 15: 1-10.

[24] Mazzoni, E. and Gaffuri, P. (2009b) Monitoring activity in e-Learning: a quantitative model based on web tracking and social network analysis. In Juan, A.A., Daradoumis, T., Xhafa, F., Caballe, S. and Faulin, J. [eds.] Monitoring and Assessment in Online Collaborative Environments: Emergent Computational Technologies for e-Learning Support (Hershey: IGI Global), chap. 7.

[25] Rindfuss, R.R. (1991) The young adult years: diversity, structural change, and fertility. Demography 28: 493-512.

[26] Goldscheider, F. (1997) Recent changes in U.S. young adult living arrangements in comparative perspective. J. Fam. Issues 18: 708-724.

[27] Goldscheider, F. (2000) Why study young adult living arrangements? A view of the second demographic transition. Paper Presented at the Workshop Leaving Home: A European Focus. Max Planck Institute for Demographic Research (Rostock), 6-8 September.

[28] Goldscheider, F. and Goldscheider, C. (1994) Leaving and returning home in 20th century America. Popul. Bull. 48: $1-35$.

[29] Coleman, J.S. (1988) Social capital in the creation of human capital. AJS 94: S95-S120 (Supplement).

[30] Bourdieu, P. and Wacquant, L. (1992) An Invitation to Reflexive Sociology (Chicago, IL: University of Chicago Press).

[31] Bargh, J.A. and McKenna, K.Y. (2004) The Internet and social life. Annu. Rev. Psychol. 55: 573-590.

[32] Helliwell, J.F.K. and Putnam, R.D.K. (2004) The social context of well-being. Philos. Trans. R Soc. B: Biol. Sci. 359: 1435-1446.

[33] Langston, C.A. and Cantor, N. (1989) Social anxiety and social constraint: when making friends is hard. J. Pers. Soc. Psychol. 56: 649-661.

[34] Paul, E. and Brier, S. (2001) Friendsickness in the transition to college: precollege predictors and college adjustment correlates. J. Couns. Dev. 79: 77-89.

[35] Wenger, E. (1998) Communities of Practice. Learning Meaning and Identity (New York: Cambridge University Press).

[36] Wenger, E. (2000) Communities of practice and social learning systems'. Organization 7(2): 225-246.

[37] Granovetter, M.S. (1973) The strength of weak Ties. AJS 78: 1360-1380.

[38] Granovetter, M.S. (1983) The strength of weak ties, a network theory revisited. Sociological Theory 1: 201-233.

[39] Putnam, R.D. (2000) Bowling Alone: The Collapse and Revival of American Community (New York: Simon \& Schuster).

[40] Ellison, N., Steinfield, C. and Lampe, C. (2007) The benefits of Facebook 'friends': social capital and college students' use of online social network sites. J. Comput. Mediated Commun. 12: 1143-1168.

[41] Subrahmanyam, K., Reich, S., Waechter, N. and EspinOZA, G. (2008) Online and offline social networks: use of social networking sites by emerging adults. J. Appl. Dev. Psychol. 29: 420-433.

[42] Hargittai, E. (2007) Whose space? Differences among users and non-users of social network sites. J. Comput. Mediated Commun. 13: 276-297.

[43] Haythornthwaite, C. (2005) Social networks and Internet connectivity effects. Inf. Commun. Soc. 8: 125-147.

[44] Herrera, M., Pacheco, M., Palomar, J. and Zavala, D. (2010) Facebook addiction Related to low self-esteem, depression and lack of social skills. Psicologia Iberoamericana 18(1): 6-18. 
[45] Karaiskos, D., Tzavellas, E., Balta, G. and PAparrigopoulos, T. (2010) P02-232-social network addiction: a new clinical disorder? Eur. Psychiatry 25: 855-855. doi: 10.1016/S0924-9338(10)70846-4.

[46] Boyd, D.M. and Ellison, N.B. (2007) Social network sites: definition, history, and scholarship. J. Comput. Mediated Commun. 13: 210-230.

[47] Dalsgand, C. (2008) Social networking sites: transparency in online education. In UNIS 2008 proceedings (Århus), 24-27 June.

[48] Griffith, S. and Liyanage, L. (2008) An introduction to the potential of social networking sites in education. In Proceedings of the Emerging Technologies Conference (University of Wollongong 1821), June, 76-81.

[49] Gray, K., Annabell, L. and Kennedy, G. (2010) Medical students' use of Facebook to support learning: insights from four case studies. Med. Teach. 32: 971-976.

[50] Santos, I.M., Hammond, M., Durli, Z. and Chou, S.Y. (2009). Is there a role for social networking sites in education? In Tatnall, A. and Jones, A. [eds.] Education and Technology for a Better World (WCCE 2009, IFIP AICT 302), 321-330. (C) IFIP International Federation for Information Processing 2009.

[51] Mazer, J.P., Murphy, R.E. and Simonds, C.J. (2007) I'll see you on 'Facebook': the effects of computer-mediated teacher self-disclosure on student motivation, affective learning, and classroom climate. Commun. Educ. 56(1): $1-17$.

[52] Steinfield, C., Ellison, N. and Lampe, C. (2008) Social capital, self-esteem, and use of online social network sites: a longitudinal analysis. J. Appl. Dev. Psychol. 29: 434-445.

[53] Tuomi-Gröhn, T. and Engeström, Y. (2003) Between Work and School: New Perspectives on Transfer and Boundary-Crossing (London: Pergamon).

[54] STAR, S.L. (1989) The structure of ill-structured solutions: boundary objects and heterogeneous distributed problem solving. In Glaser, R. and Huhns, M.N. [eds.] Distributed Artificial Intelligence, Volume II (London: Pinnan), 37-54.

[55] Griffin, P. and Cole, M. (1984) Current activity for the future: the zo-ped. In Rogoff, B. and Wertsch, J.V. [eds.] Children's Learning in the Zone of Proximal Development (San Francisco: Jossey-Bass), 45-64.

[56] Vygotsky, L.S. (1978) Mind and Society: The Development of Higher Psychological Processes (Cambridge, MA: Harvard University Press).

[57] Atтwell, G. (2007, January) Personal learning environments-the future of eLearning? eLearning Pap. 2(1): 1-8. Retrieved from http://www.elearningeuropa.info/ it/node/2632. 